\title{
La expresividad es más democrática que la originalidad. Acerca de las ideas de Kenneth Goldsmith. 14 tesis (de inspiración goldsmithiana) para una literatura en la era digital*
}

Fecha de recepción: 11 de diciembre de 2020

Fecha de aprobación: 15 de febrero de 2021

\section{Resumen}

Este artículo propone una lectura de la obra Escrituras no creativas. Gestionando el lenguaje en la era digital (traducción de Uncreative Writing. Managing Language in the Digital Age; 2015) del poeta norteamericano Kenneth Goldsmith. Esta lectura corresponde a la revisión propia del libro, está basada en resonancias personales (vínculos con otras lecturas y sobre todo con la trayectoria creativa e investigativa del autor de este artículo). El estudio está organizada por «tesis» o fragmentos que desarrollan brevemente algunas de las ideas contenidas en la propuesta de Goldsmith. Este modo de proceder ha generado reflexiones que ponen énfasis en tres planteamientos: 1) la expresividad postidentitaria como sucedánea de la originalidad creativa, 2) la relativización de las formas canónicas de la literatura como efecto del despliegue de la comunicación digital interactiva y 3) los efectos sobre el ejercicio literario en el ámbito de la cultura digital. Con esta lectura de Goldsmith se propone al final un llamado a entender las posibilidades de lo digital como una oportunidad para renovar el ejercicio literario. El artículo termina con una adenda: el cuento El hombre de la esquina, que complementa, en registro ficcional, las ideas elaboradas.

Palabras clave: escrituras no creativas, expresividad, Kenneth Goldsmith, originalidad, postidentidad.

Citar: Rodríguez, Jaime. "La expresividad es más democrática que la Originalidad. Acerca de las ideas de Kenneth Goldsmith. 14 tesis (de inspiración goldsmithiana) para una literatura en la era digital". La Palabra, núm. 41,2021,e12234. https://doi.org/10.19053/01218530.n41.2021.12234

Jaime Alejandro Rodríguez

Doctor en Filología, magíster en Literatura. Profesor titular del Departamento de Literatura de la Pontificia Universidad Javeriana.

jarodri@javeriana.edu.co is https://orcid.org/0000-0001$8220-8435$

* Artículo de reflexión.

Este artículo de reflexión se deriva de la investigación sobre literatura digital realizada en el marco del proyecto de investigación: "Interficies literarias. Preservación / potenciación de contenidos culturales nacidos digitales", patrocinado por la Pontificia Universidad Javeriana (ID de la propuesta: 0008258, correspondiente a la Convocatoria VRI-=\&-INTERDISC2018). 


\title{
Expressiveness is more Democratic than Originality. Fourteen Theses -Keneth Goldsmith Inspired for a Literature in the Digital Age
}

\begin{abstract}
This paper proposes a reading of American poet Keneth Goldsmith $>$ S Uncreative Writing. Managing Language in the Digital Age (2015) which corresponds to my personal review of the book - linked with other readings and particularly with my creative and research experience. It is organized by «theses» or pieces that briefly develop some of the ideas contained in Goldsmith >s proposal. This way of proceeding has generated three approaches: 1) post-identity expressiveness as a substitute of creative authenticity, 2) the literary canonical forms' reevaluation as an effect of the deployment of interactive digital communication, 3) the effects on literary practice in the digital culture. With this reading of Goldsmith, a call on understanding the possibilities of the digital as an opportunity to renew literary practice is proposed at the end. The paper ends with an addendum: the short story "El hombre de la esquina", which complements, in a fictional register, the ideas elaborated here.
\end{abstract}

Key words: non fictional writing, Keneth Goldsmith, posidentity, expressiveness. 


\section{A expressividade é mais democrática do que a originalidade. Acerca das ideias de Kenneth Goldsmith. 14 teses (de inspiração goldsmithiana) para uma literatura na era digital}

\section{Resumo}

Este artigo propõe uma leitura da obra do poeta norte-americano Keneth Goldsmith Escritas no criativas. Dirigindo a linguagem na era digital (do original Uncreative Writing. Managing Language in the Digital Age, 2015), por meio de uma revisão pessoal do livro baseada em ressonâncias pessoais (vínculos com outras leituras e, sobretudo, com o próprio percurso criativo e investigativo) organizadas por "teses" ou trechos que desenvolvem sucintamente algumas das ideias contidas na proposta de Goldsmith. Este modo de proceder tem gerado reflexões que fazem ênfase em três abordagens: 1) a expressividade pós-identitária como substituta da originalidade criativa, 2) a relativização de formas canônicas da literatura como efeito do desdobramento da comunicação digital interativa e 3) os efeitos sobre o exercícioliterário no âmbito da cultura digital. Com esta leitura de Goldsmith propõe-se no final um chamado ao entendimento das possibilidades do digital como uma oportunidade para renovar o exercício literário. $\mathrm{O}$ artigo termina com uma adenda: o conto $\mathrm{O}$ homem na esquina, que completa, no registro ficcional, as ideias desenvolvidas.

Palavras-chave: escritas no criativas, Keneth Goldsmith, pós-identidade, expressividade, originalidade. 
Why are so many writers now exploring strategies of copying and appropriation? It's simple: the computer encourages us to mimic its workings. If cutting and pasting were integral to the writing process, we would be mad to imagine that writers wouldn't explore and exploit those functions in ways that their creators didn't intend.

—Kenneth Goldsmith. Against Expression: An Anthology of Conceptual Writing

\section{A modo de introducción: Tesis 0 . La trampa gacheana}

Escribe tu propio Quijote es la irónica invitación que Belén Gache (s.f.) hace al usuario de su aplicación web ${ }^{1}$ para escribir algún texto inspirado en El Quijote de Cervantes, y lo es porque la aplicación digital (una pantalla que despliega una plantilla que exhorta efectivamente a escribir) es una trampa en la que se cae sin remedio. En efecto, empieza uno a escribir y pronto descubre que la interactividad por medio del teclado está predeterminada por un algoritmo que termina "escribiendo" automáticamente "El Quijote" (no sé qué tanto del libro original tiene la base de datos) por encima de cualquier intención de escritura propia. Teclear sin sentido, aleatoriamente o con intención de producir un texto genera el mismo efecto: van apareciendo una tras otra las letras que conforman el comienzo de la obra cervantina, generando al principio extrañeza y después curiosidad o incluso impotencia, o tal vez risa.

Esta trampa digital lleva a dos reflexiones que caen perfectamente en el terreno de las propuestas del libro de Kenneth Goldsmith, Escrituras no creativas (2015). Por un lado, la imposibilidad, la necedad si se quiere, de pretender que vale la pena hacerle versiones a El Quijote: ya está escrito ¿para qué más?, ¿qué más puede hacerse si no es repetirlo letra por letra? Esta primera reflexión es similar a la que expresó Borges en su legendario y a veces mal leído Pierre Menard autor del Quijote (2002). El personaje del cuento de Borges intenta reescribir la obra de Cervantes y sí que lo intenta, pero finalmente termina transcribiéndolo letra por letra, que es lo mismo que le sucede al usuario de la aplicación de Gache.

Si traemos aquí (en un ejercicio goldsmithiano) el comienzo del libro deKenneth, lo que hacemos es ofrecer, en un eco de cuatro voces, una conclusión que ya estaba dada en la reflexión de Borges; en la advertencia de Douglas Huebler, en la cita del norteamericano en su libro y ahora en mi propia cita:

En 1969... Douglas Huebler escribió:] "El mundo está lleno de objetos, más o menos interesantes; no deseo agregar ni uno más". Me he adherido a la idea de Huebler, aunque podría reutilizarla como: "el mundo está lleno de textos, más o menos interesantes; no deseo agregar ni uno más". (Goldsmith 21).

La conclusión a este primer asunto derivado de la trampa gacheneana quedaría así: $E l$ Quijote es quizás el libro más interesante de la literatura española, ya tiene todo lo que una obra literaria puede contener, ¿para qué escribir otro libro?

Se trata, en efecto, de una aplicación web que propone una plantilla para escribir texto. Acceso en http://belengache.net/ wordtoys/data/quijote/intro.htm\#) 
Ahora, una segunda reflexión se puede vincular a la otra observación que hace Borges en su cuento: la verdadera obra de Menard no es la explícita, la publicada, por lo demás prolija, sino la implícita, la imaginada, la no plasmada. Aquí hay un tema muy relevante para la creatividad: ¿cuánta obra se queda en la idea, ¿cuánta obra se queda en el plano mental cuando uno lee otra obra con la que dialoga, pelea o corrige secretamente? Es lo que le sucede a Menard: ¿cuántas versiones de El Quijote se quedaron sin escribir porque el imperativo de la originalidad se impuso y terminó reduciendo la expresividad a la simple transcripción? La transcripción obligada de El Quijote, a la que nos obliga la aplicación tramposa de Gache, genera en nuestra mente: peleas, diálogos e ideas, que si nos atrevemos a escribirlas como efecto de las emociones encontradas que produce la trampa digital (extrañeza, curiosidad, impotencia, risa) podrían generar muchos textos.

Así, la trampa gachenana es la metáfora perfecta para una de las ideas fundamentales de Goldsmith en su legendario título (Escrituras no creativas): la originalidad es un imperativo engañoso que conduce a la impotencia, la expresividad (postidentitaria) en cambio llega para refrescar los procesos de escritura, bajo la condición de aceptar que la originalidad no es la única condición para la creatividad.

\section{Tesis 1. ¿Originalidad?}

En su propuesta de Escritura no-creativa (2015) Goldsmith plantea superar el imperativo de la originalidad como indicador de creatividad y ofrece como sucedáneo de ese indicador, la expresividad. La originalidad es en realidad una condición propia de esa actitud del hombre moderno en continua tensión de progreso, que busca superar constantemente la visión tradicional y ofrecer otra, una fundacional, una radicalmente nueva. No obstante, Vattimo ya discutió la imposibilidad de mantener ese indicador como un valor en tiempos posmodernos (Rodríguez 28-30) ${ }^{2}$. Lo que Goldsmith agrega a esta observación es la idea de que la era digital, con toda la parafernalia técnica puesta en función de formas emergentes de la información y la comunicación, desmantela por completo la originalidad como la única condición de posibilidad para la creación "legítima". Es más, la originalidad queda desvelada como falacia mercantil, en el sentido de que se ha utilizado para encumbrar figuras [autores originales, capaces de crear rompimientos constantes con la tradición] que luego son vendidas como autores auténticos.

En realidad, la era digital, si seguimos los manifiestos del Critical Art Ensamble (cae), es la era de la recombinación (Rodríguez 107, 116) ${ }^{3}$; es decir, la era en que los medios técnicos facilitan la combinación de materiales prefabricados y su reensamblamiento constante (pero, también, de materiales nuevos, los digitales cuya condición natural es justamente la facilidad de recombinación). Si hay algo creativo es, entonces, la manera como se presentan esos ensambles (íntertextuales, íntermediales), que pueden parecer novedosos, pero nunca son originales.

Hago una discusión de este tema en el capítulo "Escrituras del saber" en el libro Posmodernidad, literatura y otras yerbas Hago una discusión de este tema en el capítulo Hacia una pedagogía del plagio en mi libro: 13 motivos para hablar de cibercultura (2004). 
Un ejemplo de este tipo de actividad la presenta Vicente Luis Mora, cuando describe la estrategia llamada "exnovela", que el escritor Fernández Mallo propone como término para explicar su actividad literaria "combinatoria": una exnovela, afirma el autor, puede estar compuesta por blogs preparados ad hoc por el autor específicamente para la novela o pueden ser blogs con existencia independiente de la novela, caso que constituye un acto de apropiacionismo; pero también se puede crear una web que sostenga la novela y acompañarla a través de diversos materiales como videos en YouTube o incluso crear perfiles en Facebook que sean personajes de la novela (29).

El propio Vicente Luis Mora desarrolló (con complicidad de los editores de la revista) un ejercicio que muestra otra cara del apropiacionismo: el escrito apócrifo. El número 322 de la revista española Quimera (publicado en septiembre de 2010, con una extensión de 84 páginas), dedicado al tema de Literatura y falsificación, fue escrito en su totalidad (se hizo público después) por Mora, aunque aparecieran allí nombres conocidos como Alex Socal, Rodrigo Fresán o Mario Bellatini. Acompañados éstos de nombres menos conocidos (en realidad falsos autores) que conforman una polifonía apócrifa, un ejercicio que muestra lo poco fiable que es la noción de autoría original, aunque el ejercicio de Mora sea en sí mismo, irónicamente, muy creativo.

Ahora, el movimiento cae (1998) plantea como sucedáneo del imperativo de la originalidad, el plagio utópico, denunciando de paso, la artimaña de los llamados derechos de autor que nacen como garantía financiera de los editores a finales del siglo xviii y que en nada han favorecido a los artistas.

\section{Tesis 2. Era postidentitaria}

Respecto al tema de la identidad, se hace necesario recordar lo que sobre esto plantea De Maeseneer (2017), basada en la noción sobre el carácter performativo de la identidad de Judith Butler, afirma que la identidad se ha ido despojando de esencialismos y que su construcción se fundamenta más en la negociación de un repertorio heterogéneo de influencias que el individuo pone en escena con sigo mismo y con los demás. Lo importante es, entonces, la performatividad que favorece más que una identidad única y estable, una identidad dinámica, difícil de fijar. Situación que para De Maesenner (2017) es pronunciada aún más por la globalización y las posibilidades técnicas de los nuevos dispositivos de información y comunicación, que favorecen la ampliación del espectro de influencias y facilitan el aumento del número de posibilidades identitarias.

Es por esto, que esta segunda tesis podría quedar así: Goldsmith, como muchos otros autores (valga como ejemplo y referencia reciente la de Figueroa en Imaginarios de sujeto en la era digital; 2017), llama la era postidentitaria. En particular, la posición de Goldsmith hace énfasis en la diferencia entre originalidad como rasgo del sujeto fuerte de la modernidad (Vattimo 16-23) y la expresividad como rasgo del sujeto débil de la posmodernidad (Lozano 164); rasgo exacerbado, este último, por las condiciones epistemológicas y comunicativas de la era (post) digital (Barreneche, Jaramillo, Niño, Rodríguez y Marciales 2018). Nos atreve- 
mos, incluso, a plantear que la expresividad exacerbada, vinculada a la inteligencia/creación colectiva (Lévy, 2004) y (Casacuberta, 2003), promueve una democratización de los escenarios creativos; a diferencia de la originalidad que, desde esta perspectiva, se ve como un factor excluyente.

\section{Tesis 3. La programación digital es también escritura}

Dos resonancias se producen a partir de la lectura del capítulo La venganza del texto del libro de Goldsmith. La primera lleva a la afirmación de Katz y Fink (1994) respecto a la era digital: disponemos de un nuevo alfabeto, de un nuevo sistema operativo informático: el alfabeto binario de los unos y de los ceros, que permite una manipulación mucho más interesante, inquietante y creativa de la información que el abecedario de letras de un idioma. Al fin y al cabo, si seguimos a Lévy (2007), al digitalizar la información (al llevarla a código binario) la virtualizamos, la potenciamos; pues disponemos así de un formato molecular (basado en una nueva unidad: los bytes), mucho más flexible que los formatos molares (libros, periódicos, programas de radio o televisión o películas de cine) y ganamos en la posibilidad de ensamblar y reensamblar información. Contar con unidades flexibles implica que podemos también flexibilizar su gestión, incluida la gestión creativa y estética. Ya no se trata de crear unidades molares de información o mensajes en formatos molares a partir de la combinación de estructuras lingüísticas (las narratológicas, por ejemplo), sino de combinar unidades mínimas de información y de poner en juego otras habilidades como mover, copiar, compartir o modificar información preexistente (incluso producir nueva información); así su resultado final termine envasado en formatos molares.

La segunda resonancia conduce al Jay David Bolter (1998) que denuncia el fin de la écfrasis. Según Bolter, una de las consecuencias del ascenso de la era digital es la predominancia de la imagen (no solo la imagen fija, sino la imagen dinámica, virtual y sintética) sobre la palabra, algo que hace inútil la figura retórica de la écfrasis [descripción en palabras de una imagen]. Efectivamente, presentar, editar, mover, compartir, sintetizar imágenes en plataformas digitales ahora es una operación más o menos trivial, y muchas de las aplicaciones informáticas que permiten estas funciones son transparentes para el usuario, es decir, se pueden realizar casi sin conocimientos de programación informática. Sin embargo, detrás de los nuevos materiales y de su gestión hay en realidad mucha programación, mucho lenguaje de máquina, mucho texto, así ese texto no tenga el formato de los textos alfabéticos; sino el de instrucciones en lenguaje binario. Bolter afirma que aún en un ambiente como el de la realidad virtual, que a su usuario parece totalmente inmersivo, hay realmente mucha escritura, esto es, mucho lenguaje [el lenguaje de la programación]. Esta situación no es para nada despreciable, pues si por un lado tenemos la oportunidad de extender las posibilidades de gestión de la información y la comunicación (Rodríguez, 2018); por otro lado, nos exige conocer el nuevo sistema operativo (aprender a programar) si queremos aprovecharlo mejor. 


\section{Tesis 4. El acontecimiento digital}

En el capítulo final de su libro, Goldsmith habla del lenguaje como una entidad provisional, debido a que las nuevas formas de gestión de la información y la comunicación, derivadas de la digitalización, se orientan cada vez menos a la fijación de sentido y se enfocan más en las posibilidades de la recombinación. Esta situación se puede vincular con la idea de una producción de presencia de la que habla Gumbrecht (2004). En efecto, el lenguaje 'digitalizado' al abrirse a cualquier tipo de reconstrucción y de reelaboración funcionaría más como material para la performación, como escenario performativo, que para estrategia de producción de sentido. Esta condición puede aprovecharse en sentido estético, una nueva condición estética que promovería menos la construcción de sentido y más la producción de acontecimientos (presencia en términos de Gumbrecht). Claro, esto también tiene como consecuencia una cierta incertidumbre ontológica que exige nuevas operaciones del orden posthermenéutico. Las obras que se diseñan con esta lógica "binaria" terminan promoviendo entonces la recombinación, la provisionalidad, la performance (Abuin González, 2006) y el acontecimiento.

\section{Tesis 5. Tres escenarios para la literatura digital}

Una manera de sintetizar y, a la vez, abrir el llamado que hace Goldsmith a una literatura consciente de los impactos de la era digital es distribuir en, al menos, tres los escenarios posibles de su ejercicio. Un primer escenario es el mimético: una literatura que, mediante su sistema operativo tradicional (texto y libro), ofrece imágenes y narrativas de las nuevas condiciones culturales. Es decir, una literatura que extiende el imaginario colectivo, incorporando en su expresar tradicional esas nuevas condiciones de la realidad contemporánea.

Un segundo escenario es el equivalente al del arte conceptual. El cual promueve el valor de presentar ideas, planes y diseños de obra como obra de arte misma para que sea el usuario de estas ideas el que las plasme. En el caso de las obras digitales que incluyen el diseño interactivo, esta condición se hace parte natural de la obra. 'El interactor de la obra'4 es el encargado de recorrer libremente la obra e incluso de aportar contenido, convirtiéndose así en auténtico co-creador (Casacuberta, 2004). Pero también es posible desarrollar ejercicios literarios equivalentes a los de arte conceptual en campos como la plástica. Para el caso de la narrativa, se podría ofrecer la descripción estructural de una narrativa, lo que los teóricos llamaron en su momento funciones y predicados narrativos, y convocar a usuarios a desarrollar concreciones narrativas.

Un tercer escenario implica asumir condiciones intermediales en alguna de sus tres posibilidades (Rodríguez, 2015) o enriqueciendo el ejercicio tradicional al incorporar/criticar lógicas, estéticas y efectos cognitivos de otros medios (incluido el digital); o hibridándose con otros medios para extender sus funciones ficcionales y las experiencias del usuario (hi-

$4 \quad$ Término usado por Lévy, (2007) para hablar del usuario de obras interactivas. 
permediación); o llevando las potencias de sus mundos posibles a otros formatos y plataformas para extender el universo ficcional y las audiencias (transmediación).

\section{Tesis 6. Oportunidades para la expresión}

Hay un efecto de horizontalización interesante cuando la obra de arte no pasa por el imperativo de la originalidad, vinculada con una condición trascendente (Lévy, 2007) y promueve más bien la expresividad; es decir, la capacidad de cada uno de generar contenido que expresa un momento o una condición de la situación individual. Si no tengo que (o no puedo) ser original para validar mi expresión, y si la recombinación está al orden del día, entonces la apropiación, la intertextualidad y el rémix se convierten en modelos de las posibilidades de expresión. Siguiendo a ese Gennette, reelaborado por Rubén Vélez (s.f), existen al menos treinta dos formas de intertextualidad, incluido el plagio que es como su grado cero. La apropiación intertextual consiste entonces en generar contenido a partir de un texto que es (re) elaborado siguiendo alguno de los modos intertextuales. Incluso la transcripción literal de un texto de autor es un disparador de expresividad, en la medida en que la transcripción implica lectura de texto y muy posiblemente diálogo mental con el mismo. Cuando las resonancias del texto transcrito son registradas, se produce un segundo texto paralelo que configura la obra.

Un par de ejercicios interesantes de este talante son reportados y analizados por Pantel (2013). El primero tiene que ver con el affaire literario que produjo la publicación en 2011 del libro de Fernández Mallo, El hacedor (remake), inspirado en el libro homónimo de Jorge Luis Borges. El libro de Fernández conserva la estructura y el orden de contenidos del original e incluso algunos fragmentos son transcripciones literales, pero la mayoría son reelaboraciones expresivas, resonancias personales de la lectura del libro, convertidas en obra nueva. El otro ejercicio analizado por Pantel es la construcción del poema Calle nueva que Vicente Luis Mora incluye en su libro Circular $07^{5}$. Este poema se ha elaborado apropiando versos de poemas de otros autores que tienen como referencia la calle como espacio y referencia, hasta configurar un nuevo poema no sólo inteligible, sino con un claro sentido poético que expresa la sensibilidad de Mora. ¿Cuál es esa sensibilidad? Pues la que se puede inferir de su capacidad para seleccionar, ordenar y estructurar con fragmentos de otros un poema que refleja la visión de mundo del apropiacionista.

Un caso interesante de obra que busca ser apropiada es la obra ganadora en el 2008 de poesía digital de Rui Torres, Poemas no meio do camino $^{6}$. En las antípodas de la originalidad, esta obra consiste en la programación de un generador informático de versos cuya calidad poética es decidida por el usuario, quien además de seleccionar lo que considera versos poéticos, puede construir sus propios poemas a partir de la combinación de esos versos seleccionados, tal como lo hace Vicente Luis Mora en el experimento que se acaba de describir.

editado en 2007

Laura Borrás registra el caso de Torres en su artículo: "Nuevos lectores, nuevos modos de lectura en la era digital" (2011, p. 48), el cual hace parte del libro: Literatura e internet. Nuevos textos, nuevos lectores, editado por Salvador Montesa (2011). 
Usar un generador automático de texto, en este caso, el traductor de Google puede ofrecer una experiencia similar. En esta circunstancia, el usuario busca un poema o un fragmento literario de un idioma distinto al suyo, lo pasa por el traductor y el resultado lo edita siguiendo su propia sensibilidad hasta configurar una obra que la exprese.

\section{Tesis 7. El código informático como nuevo alfabeto}

Asumir el nuevo alfabeto de los unos y ceros, y su lenguaje (el código), puede tener también dos vertientes: una es crear código mismo, es decir, programar de manera que se produzcan resultados estéticos con el lenguaje de "máquina". Es el caso de los generadores automáticos de texto que acabamos de comentar. En este caso, el programador desarrolla una máquina semiótica que, a partir de ciertas reglas que el usuario debe seguir, genera frases o textos con cierta consistencia lingüística que el usuario decide si es literaria o no. Pero además se puede administrar código, en otras palabras, hay tanta cantidad de código que podemos recuperar, que podemos recombinar, que podemos remezclar. Si entendemos código como la capacidad que tiene la digitalización, prácticamente omnipresente en nuestros contenidos, lo que podríamos hacer es aprender a recombinar ese código aún sin tener mucho conocimiento sobre la programación.

\section{Tesis 8. Palimpsesto}

Una de las figuras de la intertextualidad es el palimpsesto, que en realidad proviene de una práctica pictórica que consiste en "blanquear" un lienzo ya utilizado para reusarlo; situación que, pasado el tiempo, suele culminar en el deterioro de la pintura superpuesta con lo que la pintura original empieza a traslucir, permitiendo ver dos pinturas a la vez. Pues bien, según cuenta César Aira, en el artículo sobre la obra del escritor argentino Oswaldo Lamborguini (s.f.), éste solía usar libros viejos para sobreescribir páginas que el mismo Lamborguini blanqueaba con pintura. Ahora, un ejercicio de escritura no creativa consiste precisamente en escribir sobre páginas blanqueadas, pero que han sido leídas inmediatamente antes del blanqueo, tratando de repetir lo que acaba de leerse: apropiación por palimpsesto.

\section{Tesis 9. Nuevas materialidades, nuevas señales}

Goldsmith propone una revisión de la función de la materialidad del lenguaje en la construcción y recepción del mensaje, a partir de la observación de que el ejercicio literario tradicional ha apostado más por una transparencia del mensaje que por una ostentación del medio. En efecto, el mensaje literario, ya sea narrativo o lírico, requiere para su materialización un medio (textual) y un contenedor (libro), y con el tiempo sus estructuras informativas y comunicativas se ha automatizado tanto en la creación como en la recepción del mensaje, llevando a una condición de transparencia.

Cuando las opciones de llevar el mensaje crecen como en nuestra época digital, la experimentación con los nuevos medios (imágenes, audios, interacciones) y con los nuevos contenedores (plataformas) pasa por una revisión de las posibilidades estéticas de su manejo, 
pero además por una mirada retrospectiva y, a la vez, proyectiva de las posibilidades de la materialidad texto/libro.

Un caso de cómo ha funcionado esta revisión, es el de la verificación de cómo los poetas concretos brasileños anticiparon hace un siglo las posibilidades hoy triviales de la pantalla. En su momento, los concretistas propusieron añadir el movimiento a las funciones tradicionales de la poesía del ritmo y de la rima. Sin embargo, poner en movimiento la palabra en un medio estético como las páginas de un libro, los obligó a desarrollar simulacros sugerentes de ese movimiento a través de experimentos tipográficos, es decir, a forzar la materialidad que soportaba el lenguaje. Hoy ese movimiento de la palabra, desarrollado en pantallas y con medios digitales, se ha convertido en todo un nuevo género de la literatura digital: la palabra en movimiento (Flórez, 2016).

Otra variable de la reflexión de Goldsmith es que el conjunto medio/materialidad no sólo cumple funciones prácticas, sino que genera un sistema de relaciones muy complejas. Así el mensaje literario que fluye a partir de su propia materialidad crea las condiciones de su fluidez. Si esas condiciones cambian, cambia también la función y el sentido del mensaje. Es lo que podría suceder sí, los mensajes textuales provenientes de otros sistemas como el periodístico o el jurídico empiezan a circular en sistemas literarios. Una forma de escritura no creativa consistiría en re-situar un texto de un sistema a otro, forzando el mensaje preparado para una función (informar una noticia o persuadir al juez) a adquirir sentido en otro sistema.

Interesante el caso de Vanesa Plays, abogada, cuyo oficio es escribir memorandos para la Corte Suprema de Justicia norteamericana sobre casos (por lo general, la defensa de criminales consumados en busca de rebajas de penas) que deben ser presentados ante los jueces y que son escritos en un lenguaje propio de ese marco jurídico. (citado en Goldsmith 2015: 124), Sin embargo Plays también los presenta, sin alterarlos, incluso leyéndolos de la manera fría como los presenta en la corte, en reuniones o festivales poéticos. Los pone en un marco de recepción literario para producir efectos poéticos, son textos no derivados de una escritura creativa, sino de la recepción de sus textos por parte de una audiencia predispuesta al mensaje poético, una audiencia que termina apreciando el drama de los pactos que gestiona la abogada, procesados a través de la subjetividad poética de cada receptor. Claramente no hay escritura creativa aquí, pero sus efectos en este resituacionismo son los equivalentes a los de una escritura creativa.

En realidad, ese aparente hiperrealismo tiene un truco que termina siendo parecido al truco develado por los formalistas al estudiar el discurso poético, y es que lo que se hace con textos o con realidades directas o discursos no literarios es sacarlos de su propio contexto (efecto de extrañamiento, dirían los formalistas) y ponerlos en otro para hacerlos ver de una forma distinta a como serían percibidos en su ambiente natural. Dicho de otra forma, literalmente desnaturalizarlos, ya no desde un ejercicio creativo sino a partir de una alteración o contaminación de sistemas comunicativos hasta ahora diferenciados. Todo esto demuestra que, lo que logra como efecto la escritura creativa lo pueden alcanzar también otras expresiones si alteramos su situación. 
El propio Goldsmith realizó un ejercicio de resituacionismo, cuando presentó como novela (un libro que anunciaba ser una novela) la transcripción completa del contenido de un número del periódico The New York Times (el correspondiente al viernes 1 de septiembre del 2000), bajo el título Day. El lector, que si bien puede llegar a descubrir rápidamente que lo que lee no es una novela canónica, queda inducido a leer el texto como si se tratara de una novela, poniendo en cuestión la artificialidad de los sistemas comunicativos.

La eclosión mediática contemporánea nos está obligando a lidiar con nuevos lenguajes y nuevas materialidades concomitantes. Una imagen sugerente que ofrece Goldsmith, que da una idea de esta creciente diversidad y que podría ser el insumo para un relato (de hecho, en la adenda de este artículo se muestra un relato inspirado en esta tesis goldsmithiana), es la de estar parados en una esquina cualquiera de nuestras ciudades. Sin darnos cuenta en esa esquina, porque las nuevas materialidades parecen intangibles mezcladas con el aire que respiramos y mimetizadas en las superficies a nuestro alrededor, se cruzan ondas de todas clases: señales de radio, televisión, internet, datos móviles, virus biológicos y toda clase de flujos de información quizá ininteligibles pero presentes. Ese es el reto: lidiar; es decir, gestionar, intervenir, potenciar estos flujos para darles sentidos simbólicos y colectivos, que es lo que ha hecho la literatura siempre, aun cuando es concentrada en un solo medio: la palabra escrita llevada por el libro.

\section{Tesis 10. Robots y la escritura no creativa}

Llevamos siglos haciendo relatos literarios. Los esfuerzos de los teóricos de mitad del siglo pasado permitieron reconocer modelos "universales" de la narrativa literaria, develaron sus estructuras. En la actualidad, con la posibilidad de extender por medios digitales y redes sociales el ejercicio de la escritura (enriquecida si, por la incorporación de otros medios), se ha permitido otro nivel a ese reconocimiento de patrones narrativos. Es el caso de la plataforma Wattpad, que ya aplica la inteligencia artificial para la captura de datos de sus usuarios. Tanto los millones de historias (proveniente nada menos que de 65 millones de usuarios), afirman en su artículo Suárez y Cáceres 2019: como el comportamiento de los autores y lectores, así como sus interacciones registradas por la plataforma, configuran un almacén de información narrativa con los cuales se van a alimentar los nuevos procesos de aprendizaje de los robots creativos narradores. Nada más cerca y más diciente que este escenario "machine learning" para entender lo que Goldsmith quiere definir como escritura no creativa.

\section{Tesis 11. Interviniendo el código}

Una primera síntesis: literatura es manipular lenguaje para crear información añadida (Lusato, 1982). Hoy tendríamos al menos dos niveles de trabajo que pueden combinarse: el nivel del lenguaje natural que tiene también su propio código en el alfabeto tradicional y un nivel de lenguaje que es el del lenguaje digital, el nuevo alfabeto, es el de los unos y ceros. Un escrito hoy debería asumir entonces una y otra, de una manera contemporánea. En el primer caso, una manipulación que se puede hacer a través del arte de la recombinación, en otras palabras, son cuerpos literarios ya formados que yo aprovecho para reensamblar y para 
reescribir. En el segundo caso, es trabajar con el código ya sea creándolo o manipulándolo (lo cual implicaría una realfabetización), como lo que hace, por ejemplo, Goldsmith cuando introduce el código textual en el código de imagen o de un audio.

Este último ejercicio, el de la intervención del código, tiene un antecedente famoso en una presentación de Nam June Paik en el 1963 (que inició una forma del vídeo arte: las videoesculturas). Este autor realizó un vídeo en el que mostraba cómo, haciendo uso de un electroimán, se podía distorsionar la imagen que transmitía en ese momento un televisor, develando cierta fragilidad del contenido televisivo por la intervención sobre su materialidad, al reducir las señales televisivas a pura señales luminosas.

Tuve la oportunidad de ver una intervención análoga, pero sobre código digital en el cuarto festival de la ELO en julio de 2017, en Porto (Portugal). La obra de David Hall tenía por título: A Brief History of Loss (LabTV UFP). En esta obra, el autor presenta en vivo a su audiencia, un ejercicio desplegado en tres ventanas de la pantalla del computador, desarrollándose en tiempo real. En la ventana izquierda, hay una foto antigua tipo álbum familiar, en la que aparece una mujer acompañada de su pequeña hija. En la ventana central, inicialmente en blanco, el autor escribe un relato que narra (y es a la vez reproducido por una voz robótica) la pérdida que significó para la niña la muerte de su madre. En la tercera ventana, está el código correspondiente a la imagen digital de la ventana de la izquierda. Los espectadores pueden ver cómo el autor empieza a manipular el código y su efecto en la imagen, este consiste en que la foto se va "borrando" de abajo hacia arriba, creando el efecto de la desaparición no solo de la imagen, sino de las personas representadas.

\section{Tesis 12. Desnudando el texto. La literatura post identitaria}

Otra de las observaciones de Goldsmith sobre las posibilidades de la escritura no creativa, además de las ya mencionadas del resituacionismo y de la anticipación concretista de la pantalla, es lo que llama el texto al desnudo. En efecto, el texto puesto en un contenedor como el libro (o el periódico o la revista) genera, gracias a los elementos para textuales (carátulas, editoriales, encabezadas, etc.) un efecto de autoridad. La carátula generalmente resalta el nombre del autor del libro (la fuente de autoridad: ¡ah!, es una obra de García Márquez, debe ser buena) y los periódicos en sus encabezados nos recuerdan que su autoridad proviene de su institucionalidad ( $j a h$ !, es una noticia del New York Times, debe ser cierta). Pero si tuviéramos el texto sin esa parafernalia paratextual, la situación cambia: no tendríamos un referente de calidad o de veracidad y hasta podría ser un insumo para la apropiación. De esta situación, Goldsmith deriva la idea de una literatura post identitaria. Es decir, si la calidad de un texto depende de su identidad con una fuente de autoridad, al retirar esa referencia identitaria, el texto adquiere una condición distinta, más flexible, menos cerrada y más abierta a su apreciación.

Un ejemplo de la parálisis expresiva que produce la figura autoritaria (y trascendente) de un autor-creador, la estudió (y de alguna manera, la solucionó) el docente Juan Carlos Valencia (2013), quien examinó un evento anual que se desarrolló en el municipio de Nocaima 
(Cundinamarca, Colombia), en la primera década del nuevo milenio (festival literario), y que tenía como objetivo incentivar y cualificar los procesos de lectoescritura de estudiantes de una escuela básica en este pueblo, a través del "ejemplo" de modelos de escritores que eran invitados al festival. Lo que logra aclarar este investigador es que el "efecto de autoridad" de estos invitados producía una especie de parálisis expresiva, dada la distancia entre lo que se proponía como modelos de escritura literaria y las condiciones que los niños tenían para alcanzar una escritura cercana al modelo. Al cambiar la perspectiva y observar la escritura posible y real entre los niños; además de ponerla en circulación, exponerla a su valoración y sobre todo gestionarla a través de plataformas digitales y blogs, se logró romper con la parálisis y empezó a fluir una escritura más inmanente, más real.

\section{Tesis 13. La escritura conceptual}

Otro foco de atención que propone Goldsmith es lo que podríamos llamar escritura conceptual. Esta es una enunciación de la intención del mensaje o incluso las meras instrucciones para crear un objeto que nunca se ha realizado o que será realizado infinitamente de una manera plural, dependiendo del usuario, de dichas instrucciones y de su imaginación o de su voluntad de crearlo. Es una cara más de la escritura no creativa en el sentido en que se propone más el concepto que la elaboración, lo que es en últimas, una forma de negarse a la creación en el sentido canónico de un proceso creativo.

Cito, aquí largamente, parte de la presentación que el propio Goldsmith hace de una extensa antología de escritura conceptual (Dworkin y Goldsmith: 2011) en la que reconoce que hay una larga historia de esta práctica; ahora facilitada por la extensión del uso de las facilidades digitales:

Aunque la revolución digital ha fomentado un entorno fértil en el que la escritura conceptual puede prosperar, las raíces de este tipo de escritura se remontan a los procesos mecánicos de los escribas medievales o los métodos de composición procesal de Wolfgang Amadeus Mozart. La vida de Johnson de James Boswell, una acumulación meticulosa y obsesiva de información (repleta de glosas similares a la forma en que funcionan los comentarios en los blogs de hoy) fue premonitoria de la escritura de la actualidad.

El modernismo proporcionó una serie de precedentes, incluidos los escritos de moda falsificados de Stéphane Mallarmé, los experimentos de Erik Satie con la repetición y el aburrimiento, los readymades de Duchamp y el abrazo de Francis Picabia de las técnicas de dibujo mecánico. Del mismo modo, los tomos épicamente indescifrables de Gertrude Stein y las obras de collage radicales y multilingües de Ezra Pound podrían considerarse proto-conceptuales. Quizás el ejemplo más concreto de "información en movimiento" es el Proyecto The Arcades de Walter Benjamin, un trabajo que recopila más de novecientas páginas de notas.

A mediados de siglo, con el advenimiento de la tecnología generalizada, vemos movimientos tan diversos como musique concrète, poesía concreta y Oulipo y Fluxus retomando el hilo. Los textos como los escritos de Walter Benjamin en los medios de comunicación, la práctica de 
la vida cotidiana de Michel de Certeau, las mitologías de Roland Barthes y las teorías de simulacros de Jean Baudrillard proporcionan un marco teórico ${ }^{7}$ (Dworkin y Goldsmith xx )

Otra forma de escritura no creativa sería resistirse a la elaboración ideológica o moralista a través de estrategias literarias y presentar de forma directa lo que se observa un antecedente es el noveau roman francés de la década de 1960; de modo que, el sentido ético o político de lo registrado dependa del lector que puede decidir, sin tener que resolver segundas referencias, lo que pudiera haber detrás de los hechos o escenarios presentados por el escritor. En últimas, este tipo de escritura es una especie de radicalización de cierta tendencia hiperrealista que termina en una escritura no creativa.

\section{Conclusiones}

La gran advertencia de Goldsmith es que las formas como se ha encumbrado la literatura, como expresión singular con capacidades y funciones excepcionales, en realidad resulta ser una falacia apenas se comienza a examinar de cerca los elementos de los que depende su funcionalidad y también su relación con otros sistemas expresivos.

Es claro que las formas 'creativas' de la literatura conducen a efectos cognitivos de la realidad y a goces estéticos especiales, así como a refiguraciones de nuestro horizonte de experiencias; no obstante, en primer lugar, no es la única manera de lograr dichos efectos, como tampoco están sustentados en la figura del autor exclusivamente.

Schaeffer (2002) ha propuesto relativizar las funciones ficcionales de la literatura, advirtiendo que se han desplegado otros sistemas expresivos que cumplen las mismas funciones generales (tradicionalmente la fotografía, el cómic, el audiovisual y el teatro; y más recientemente los relatos digitales, la realidad virtual y agrego las narrativas transmedia). Esta extensión de la función ficcional implica, sin embargo, la conciencia de que los efectos dependen de una pragmática que involucra al creador de la obra y a su receptor en un contrato estricto, cuyo cumplimiento es necesario para que se dé la ficcionalidad (a un vector de inmersión, una postura de inmersión).

Respecto a la idea de una singularidad de capacidades del escritor literario para ofrecer textos especiales que brinden las funciones ficcionales, capacidades ligadas a una idea de originalidad, Goldsmith contrapone la idea de una expresividad. Es decir, la capacidad de ofrecer discursos que cada uno de nosotros tenemos sin tener como soporte una condición de fuente de autoridad; sino, más bien, en una lógica post identitaria, una capacidad a través del apropiacionismo, la creación colectiva y el resituacionismo de expresar ideas, de configurar obras y de vincular a otros en la dinámica de los efectos que hasta ahora se le atribuían sólo a ejercicios de figuras de autoridad.

Traducción propia. 
Quebrando el "cuello" a la estricta pragmática de Schaeffer, se puede ahora asegurar que el entrenamiento que se ha tenido para asegurar posturas de inmersión literarias nos certifica como sujetos que pueden recibir, elaborar y, de algún modo, crear y aprovechar los efectos cognitivos de los dispositivos ficcionales aún a partir de dispositivos no literarios o ficcionales. Como cuando extraemos la lección de humanidad que nos ofrece con su discurso técnico un abogado que nos presenta sus casos de defensa de criminales consumados. No hay allí ni intención, ni estrategia poética, ni siquiera originalidad; sin embargo, la audiencia, alterando su contrato pragmático, recibe esas narrativas como literarias.

Entender que en la actualidad se dispone tanto de diversidad de lenguajes como de libertad de expresión y libertad de recepción, nos lleva a otro de los mensajes goldsmithianos: se debe desaprender las formas de gestión del lenguaje para aprovechar mejor el escenario contemporáneo de provisionalidad lingüística y pragmática, y actuar en consecuencia.

Es cierto que esa conciencia de provisionalidad, diversidad y libertad nos la ha marcado la virtualización propia de lo digital; pero eso no quiere decir que su resolución expresiva sea solamente digital. Lo digital es todavía un territorio por explorar; no obstante, por ahora se puede ir incorporando muchas de sus técnicas, hallazgos y gestiones en nuestros ejercicios más tradicionales.

\section{Referencias}

Abuin González, Ángel Escenarios del caos. Entre la hipertextualidad y la performance en la era electrónica. Valencia: Tirant lo Blanch, 2006.

Aira, César. Osvaldo Lamborghini and His Work. Asymptote.com. web.

Barreneche, Carlos. Niño Bernal, Raúl. Rodríguez Ruiz, Jaime Alejandro. Jaramillo Marín, Jefferson y Marciales Vivas, Gloria Patricia. Las ciencias sociales y humanas en la actual sociedad del conocimiento. Escenarios de indagación ínter y transdisciplinar. Bogotá: Editorial Pontificia Universidad Javeriana, 2018

Bolter, Jay David. "Ekpbrasis, realidad virtual y el futuro de la escritura”. El futuro del libro. ¿Esto matará eso?, Barcelona, Paidós, 1998, págs. 250-278.

Borges, Jorge Luis “Pierre Menard autor de El quijote”. Ficciones. Madrid: Alianza Editorial, 2002, págs. 23-35.

Borrás Castanyer, Laura. "Nuevos lectores, nuevos modos de lectura en la era digital". Literatura e internet. Nuevos textos, nuevos lectores. Actas del XX Congreso de Literatura Española Contemporánea, Universidad de Málaga, 2011, págs. 41-66. web 
Critical Art Ensemble. "Plagio utópico e hipertextualidad en la cultura electrónica”. El Paseante. La revolución digital y sus dilemas, Madrid, Siruela, 1998, págs. 27-28.

Casacuberta, David Creación colectiva. En Internet el creador es el público. Barcelona, Gedisa, 2003

De Maeseneer. "La música popular en la narrativa caribeña contemporánea como seña de identidad(es)". XII Seminario Internacional de Estudios del Caribe, 2015. Crisis, diálogos y desafios en el gran Caribe. (pp. 455-469). Cartagena de Indias: Universidad de Cartagena - Instituto Internacional de Estudios del Caribe - Grupo de Investigación Sociedad, Cultura y Política en el Caribe colombiano, 2017, págs. 455-469. Web.

Dworking, Craig y Goldsmith, Kenneth. (Eds.). Against Expression. An Anthology of Conceptual Writing. Illinois: Northwestern University Press, 2011.

Figueroa-Sarriera, Heidi Imaginarios del sujeto en la era digital. Post(identidades) contemporáneas. Quito: Ediciones CIESPAL, 2017

Flórez, Leonardo. Los géneros digitales literarios. 80 grados Prensa sin Prisa. Web. 23 de diciembre 2020.

Gache, Belén. "Escribe tu propio Quijote”. Wordtoys. Web 28 de noviembre. 2020

Goldsmith, Kenneth. Escritura no-creativas. Gestionando el lenguaje en la era digital. Trad. Alan Page. Buenos Aires: Caja Negra Editora, 2015

Gumbrecht, Hans Ulrich. Producción de presencia. Lo que el significado no puede transmitir. México: Universidad Iberoamericana, 2004

Gregorian, Vartan. "Technology, Scholarship, and the Humanities: The Implications of Electronic Information.” Leonardo, vol. 27 no. 2, 1994, p. 129-133. Project MUSE muse. jhu.edu/article/607890.

LabTV UFP. David Hall, “A brief history of loss”, 2017. Web. 15 de enero. 2021.

Lévy, Pierre. Inteligencia colectiva. Por un antropología del ciberespacio, 2004. . Cibercultura. La cultura de la sociedad digital. Barcelona: Anthropos, 2007.

Lozano, Maria del Pilar. La novela española posmoderna. Madrid: Arco Libros, 2007.

Lussato, Bruno. El desafío informático. Presente y futuro de una explosión tecnológica. Barcelona: Editorial Planeta, 1982. 
Mora, Vicente Luis “Acercamiento al problema terminológico de la narratividad transmedia". Caracteres. Web. 13 de mayo. 2014.

Pantel, Alice“Cuando el escritor se convierte en un hacker: impacto de las nuevas tecnologías en la novela española actual. (Vicente Luis Mora y Agustín Fernández Mallo)”. LetraI, (11) 54-69, 2013.

Quimera. Revista de Literatura. Número 322. Dossier: Literatura y falsificación, 2010. Recuperado de https://dialnet.unirioja.es/ejemplar/248899

Rodríguez, Jaime Alejandro Posmodernidad, literatura y otras yerbas. Bogotá, Editorial Pontificia Universidad Javeriana, 2000.

.Trece motivos para hablar de cibercultura. Bogotá, Editorial Pontificia Universidad Javeriana, 2004.

Sueños, plataformas e inspiración ¿Tiene la literatura algún rol relevante en los escenarios creativos contemporáneos? I Encuentro de programas de creación literaria y escrituras creativas Bogotá, Universidad Nacional, 24-27 de marzo, 2015.

.Del autor junta palabras al autor junta palabras, imágenes, sonidos, interactividades, algoritmos: la gestión literaria en la era (post) digital". La Palabra, (32), 2018. Doi: https://doi.org/10.19053/01218530.n32.2018.8159

Schaeffer, Jean-Marie. ¿Por qué la ficción? Madrid: Ediciones Lengua de Trapo.2002

Suárez, Juan Luis y Cáceres, Dago. "Literatura y creatividad artificial en la época de la singularidad”. Cubana de Ciencias Informáticas, 13(1) 158-175, 2019. Recuperado de http://scielo.sld.cu/scielo.php?script=sci_arttext\&pid=S2227-18992019000100158

Torres, Rui. Poemas no meio do caminho. (2018) Web. Recuperado de https://telepoesis.net/ caminho/poemasnomeiodocaminho.pdf

Valencia, Juan Carlos. Obligatoriedad o placer en la lectura: el caso en la vereda El Jagual, Nocaima, Cundinamarca. Periodo 2008-2011. Trabajo de grado, Pontificia Universidad Javeriana, Bogotá, 2013. https://tinyurl.com/y72g6jdl

Vattimo, Gianni. “El consumidor consumido". Fin de siglo, Revista de la Universidad del Valle, (2) 16-23, 1992

Vélez Correa, Roberto. Misterios y encantos de la intertextualidad. Manizales: Universidad de Caldas, s.f. 


\section{Adenda}

\section{El hombre de la esquina}

\section{Un cuento de inspiración Goldsmithiana}

\section{Presentación}

La idea del relato surge de tres condiciones: primera, la respuesta a la pregunta por la posibilidad de resolver, en términos narrativos literarios, la evidencia de que en los tiempos más recientes nos hemos visto abocados a lidiar con una gran cantidad de medios, plataformas y lenguajes emergentes; lo que nos hace, a la vez, muy potentes en términos de comunicación. Pero, al mismo tiempo, muy vulnerables como sujetos presionados por la gestión de la información que se despliega por dicha eclosión mediática.

El cuento toma como eje la imagen intangible y real de la cantidad de señales con las que nos "tropezamos" cuando deambulamos por la ciudad, por cualquier esquina. "¿Somos conscientes del 'ruido' que nos envuelve sin evidencia?" No, porque estamos atados a la materialidad de los dispositivos que procesan esas señales invisibles y que están, sin embargo, presentes de forma ubicua.

Esta condición de la multiplicidad de lenguajes y la necesidad imperiosa de gestionarlos se ha exacerbado por la transformación de las condiciones de comunicación, a la que nos ha llevado la condición reciente de confinamiento. Esa es la segunda condición de origen del relato. De hecho, el texto, aunque imaginado mucho antes, se resuelve durante los días 27 y 28 de marzo de 2020.

La tercera condición es el reto. A mis estudiantes del taller de narrativa de la Universidad Javeriana, les propuse desarrollar ejercicios relacionados con la situación a la que todos nos vimos obligados intempestivamente: el encierro, el cuidado, la comunicación remota y digital, y todo lo que esto implica para nuestra cotidianidad. Quise ser el primero en escribir y compartir una experiencia creativa así condicionada.

El cuento, dirigido a jóvenes y adultos, utiliza una técnica de lo fantástico (el canal insólito) para exponer la sutil relación entre lo singular y lo cotidiano que de pronto cualquiera de nosotros se encuentra si nos abrimos a esa percepción.

El relato narra la situación singular de Juan, un cuarentón fracasado, quien descubre que en la esquina antes de llegar a su casa, se produce un fenómeno extraño que solo él parece percibir. Hay una especie de canal de señales muy diversas cuyas sintonía él asocia al principio con síntomas emocionales y mentales que lo vienen acosando. No obstante, cuando se atreve a afrontar la situación descubre que su cuerpo y su mente tienen la capacidad de acceder a ese mundo de lenguajes y señales que, aunque parezca caótico y confuso, tiene un sentido que parece haber estado destinado para él. Ese mundo nuevo, sin embargo, lo pone en 
una situación de extrañamiento para los demás, sus pocos amigos y parientes, y para quienes deciden sobre su salud (mental). Termina confinado en un manicomio, pero, a la vez, con licencia para ejercer ciertas actividades tan excepcionales como insulsas; sin embargo, se convierten en el sentido de su vida.

Hay detrás de todo esto una metáfora de nuestros tiempos recientes, en los que el mundo conocido, nuestra zona de confort se ha desmoronado de alguna manera, se ha vuelto extraño y, entonces, imaginamos o soñamos con otros mundos, otros canales de contacto, otros sentidos de la vida. Juan es cada uno de nosotros, habitamos un mundo loco, un mundo patas arriba, aunque, si somos lo suficientemente sensibles nos está abriendo las puertas a condiciones inéditas y posibles. Basta con afrontarlas, con admitir esas novedades para explorar sus posibilidades y sentidos. Son tiempos de locura, pero también de los locos que nos atrevemos a habitar mundos nuevos.

\section{El hombre de la esquina}

\section{Jaime Alejandro Rodríguez}

Los primeros síntomas fueron sutiles, casi imperceptibles, desdeñables. Un ruido extraño en la noche que interrumpía su sueño, pero que nunca se dejaba reconocer; algún efluvio dulzón que se atravesaba de pronto frente a su cara, pero que desaparecía sin rastro; un golpe de aire en el recinto cerrado de su alcoba que siempre se escabullía por debajo de la puerta, como si estuviera gastándole una inocente broma; el chasquido imposible de unos dedos detrás de él que a veces confundía con la prueba (el deseo), fallida(o) del regreso del ser amado.

Para qué comentarlo, para qué escribirlo, pendejadas que le pasan a un hombre que vive solo. Explicaciones incluidas, sobre todo las científicas, pero también las extraídas de una sicología de pacotilla o de las informaciones poco fiables de internet (que él seguía consultando más por inercia que por otra cosa), había de sobra. En la oficina tenía que aparentar entereza, y dignidad ante los familiares, siempre al acecho de una oportunidad para expresar su falsa compasión, los apócrifos deseos de bienestar que en realidad escondían el mórbido regocijo por su fracaso. Lo tenía claro, haber llegado a los cuarenta sin un empleo fijo, sin una relación estable, sin hijos, con dos gatos viejos que ya no le ofrecían sino problemas, no era la situación ideal para nadie.

Se había propuesto no dejarse obsesionar por los pequeños signos que seguían acompañándolo cada vez con más frecuencia, pero bastaba que estuviera o se sintiera solo en casa para que empezara a percibirlos. Y comenzaron a sumarse más. Una luz a veces parpadeante, a veces concentrada en un punto, a veces danzante, que se instalaba a la media noche, por minutos encima de la puerta entreabierta de su cuarto, un susurro inhumano que lo aturdía cuando cambiaba de posición en la cama, un cosquilleo incómodo en los pies que lo hacía convulsionar casi siempre al amanecer. 
Pero la preocupación llegó cuando los signos empezaron a tomarse los espacios del día. Al principio como resonancias de la noche, después en los lapsos de pausa matutina en la oficina y en la antesala de la salida del trabajo, para empatar luego con la hora del sueño. “¡No juancho, mi hermano!”, le escribió Nico por el WhatsApp, “eso ya cambió de nivel, yo conozco una vieja que te puede ayudar, a mí me ha sacado de varios baches y no es carera. Y hazlo pronto, antes que inicies a escuchar vocecitas, ijajajaja!”.

Lo de las vocecitas llegó pronto. Una ráfaga de sonoridades de las que alcanzaba a distinguir estridencias, zumbidos y, si, vocablos definitivamente humanos, lo atacaban cada vez que pasaba por la última esquina que tenía que cruzar antes de llegar al edificio. "Claro, Julieta, he probado todas las variantes: eludir la esquina, pasar despacio, cruzar rápido, taparme los oídos, abrir grande la boca, cambiar la hora de tránsito, de todo y está comprobado, es un espacio muy preciso el que trae esas sonoridades, como una especie de canal muy fino por el que se cuelan las señales". "Bueno Juan, puede ser un episodio psicótico o el origen de una esquizofrenia, tendremos que trabajar duro para identificar el tipo de dificultad, por ahora, te voy a recetar estos medicamentos".

“¿¿Dificultad?!”, “sí, dificultad”, “dijo dificultad, ¿estás seguro?” "Que si, Clarita, eso fue lo que me dijo y también me recomendó conversar contigo sobre el uso de los medicamentos, por eso te molesto”. "¡Ah!, y yo que alcancé a creer que querías verme y recordar nuestros bellos viejos tiempos, ijajajaja! Mentiras, claro que sí, puedo contarte que me ha ido muy bien, pero eso sí, tienes que ser muy juicioso con la dosis y no dejar de tomarlos nunca, ni por nada, muy juicioso con eso. Yo no he vuelto a tener problemas, ni en el trabajo, ni en la casa, ya Daniel y mi hijito, Alejo, ni se acuerdan muy bien”.

Por un par de semanas, Juan evitó el encuentro con el canal, pero notó que la percepción de los otros signos se exacerbó, las luces, los ruidos, los olores, las sensaciones y ahora hasta las emociones, ganas de llorar a cada rato, por ratos sensación inexplicable de desamparo, y otros de enojo. "Es por el medicamento, Juan. Es que el cuerpo se pone alerta y entonces te haces más sensible, pero irá pasando, no te preocupes. Ya probaremos lo de tu canal a ver qué pasa, por ahora lo vamos a evitar".

"Estoy durmiendo poco, Nico, pero Julieta achaca todo al periodo de asimilación con el medicamento, ¡no sé!, he empezado a sentir como desconfianza... si, si, del medicamento, pero también de Julieta. Ya llevamos un mes y siento que he empeorado. No sé".

Se decidió a hacerlo sin autorización. La creciente incomodidad de sus insomnios lo llevó a la desesperada conclusión de que enfrentar el canal era lo que debía hacer. "¡Si seguro!, yo también creo que debes tomar el toro por los cuernos", le había concedido Margarita, su hermana, quien después de enterarse de su situación se había vuelto a acercar, olvidando sus desavenencias de largos años.

Pero sucedió lo que menos había deseado. Catalina también se enteró y aunque al comienzo su ex se portó compasiva y hasta tierna, no tardó en ponerse intensa. "No me sorpren- 
de, era algo que en cualquier momento iba a explotar, ¡ Juan, es que con esa mujer que tienes por madre antes no enloqueciste antes!" "La verdad agradezco que ya no estemos juntos, no sé si habría podido soportar tus alucinaciones, además de tus cambios de ánimo y tu mediocridad". "Entonces ¿para qué me llamas?, ¿no te entiendo?, no pedí nunca que te acercaras con tu falsa compasión y tus ínfulas moralistas. Lo mejor es que te alejes de nuevo y para siempre. Ando muy embolatado como para que ahora enredes más las cosas".

Catalina era una mujer hermosa, pero de una personalidad complicada. La típica niña consentida, acostumbrada a que las cosas sucedieran simplemente porque las deseaba, incluso antes de solicitarlas. Juan lo supo a los pocos meses, no obstante, tardó dos largos años para decidir la separación. Fueron meses difíciles, amargos y ahora se pregunta si lo que le pasa no son las secuelas de esa larga intoxicación. "Puede ser, mi hermano, esa vieja trae malas energías, yo de ti contrataba una limpia para ti y para ese apartamento. Debe estar lleno de malas energías". "¡Sabes que sí, Nico!, pero no sé si tenga que comentárselo antes a Julieta, ¿qué tal que me tire el tratamiento?" "iQue va, viejo!, eso no tiene nada”.

En el pequeño cuarto del patio encontró unas fotos de la época, dos caimanes para el pelo y varias fotocopias de lecturas que pertenecían a Catalina. Creyó ver pelos rubios y largos que también podrían ser de ella en los cajones de la mesita de noche, aunque tal vez fueran de la chica que ahora le ayudaba con el aseo. También había un pocillo y varios platos en la cocina que Cata había comprado y las bolsas para los limpiones que había llevado cuando se pasó a vivir con él. Se sorprendió con el inventario de objetos y efectos que fueron apareciendo y que él nunca había relacionado con la presencia remanente de Catalina.

Armado con guantes, trapeador, toallas y balde nuevo, emprendió el proceso de limpia que había seleccionado de las varias opciones en internet. Sal y vinagre para baños y cocina, agua florida para las habitaciones y muebles, un buen sahumerio para todo el apartamento y cristales de cuarzo y amatista distribuidos estratégicamente por todo el apartamento. Los gatos, al comienzo un poco extrañados, terminaron acompañándolo, como validando su labor. Eso le dio esperanzas.

No sólo quedó exhausto después de la tarea, sino con un sentimiento blended de lo peor, mezcla de tristeza, nostalgia, rabia, frustración, arrepentimiento $\mathrm{y}$, sobre todo, vergüenza. A pesar de que no fue mucha la energía que le exigió la limpieza del apartamento, terminó finalmente tendido encima de la cama y durmió toda la noche, sin cambiarse, sin arroparse, derechito hasta el amanecer, como hacía rato no lo lograba.

Pero no fue un sueño tranquilo, por un extraño escenario que alternaba una tarima de modelaje y un callejón de mala muerte, desfilaron todos sus muertos conocidos. Curiosamente, los varones, su padre y su abuelo; caminaban graciosa y festivamente por la tarima, generando en él, en su yo onírico, una suerte de sentimiento de paz y alegría. En cambio, las mujeres, su abuela, una novia aniquilada por el cáncer y una mujer desconocida lo llevaban a un callejón sin salida, donde lo acorralaban, una por una, contra la pared del fondo, lo acariciaban y lo apretaban con sus brazos desnudos y sus manos terminadas en largas uñas, pro- 
vocando el ahogo, la angustia. Hacia las seis de la mañana, despertó justo después de uno de esos ahogos y se quedó paralizado un buen rato, recordando, reviviendo la horrible pesadilla.

No sirvió de nada. Después de dos días tranquilos y tras una sesión con su terapista, Juan volvió a sufrir todo el acoso de las señales. El sentimiento de desamparo lo asaltó de nuevo mientras se dirigía al apartamento, después de la salida del trabajo. Hizo la cuenta y se dio cuenta de que no tenía en realidad mucha gente a quien acudir. Es cierto que tenía más de mil amigos, sumando sus contactos de Twitter, Face e Instagram, y que estaba adscrito a unos cinco grupos de WhatsApp, pero solo podía recurrir a Nico y a Margarita para estas afugias, con Cata ni hablar y Julieta era apenas una especie de bot que solo ofrecía respuestas prefabricadas. Los pasos que lo conducían a su apartamento se hicieron lentos, casi dolorosos.

Entonces lo decidió, pasar por el canal, asumir las consecuencias. Vio algunas personas cruzando la calle, así que esperó, furtivo, un rato hasta que supo que era el momento. No tardó en ubicar la ortogonal que parecía bajar del cielo y se ubicó debajo de ella. Al comienzo tuvo la misma experiencia de los primeros días, zumbidos, ruidos extraños, ininteligibles y, de vez en cuando, un sonido similar al habla humana. Empezó a moverse un poco, a veces para rodear el canal y entrar a él desde distintos puntos, a veces para probar el ancho de la circunferencia del canal (no más de ochenta centímetros). En otro momento, como si se tratara del chorro frío de una ducha imaginaria, pasaba solo los pies o las manos y luego si entraba su cabeza. Descubrió que, cuando se ubicaba lo más erguido posible debajo del tubo invisible, podía distinguir mejor los sonidos, incluso pudo discernir el gorjeo de un pájaro y de pronto pudo escuchar las voces de gente.

Fue un poco difícil, primero porque la mayor parte del tiempo se congregaban muchas voces, como si fuera una multitud que vociferara sin orden, a veces porque la lengua era extraña, pero después de un tiempo logró filtrar voces que hablaban en español.

¿Cuánto tiempo estuvo allí parado? No lo sabía, pero se sintió sorprendido porque al otro lado de la acera vio un grupo de vecinos que se había reunido y ahora lo miraba con extrañeza y hasta con recelo. Las mujeres se llevaban la mano a la boca para secretear a las otras, los niños se reían como si se tratara de alguna comedia y los hombres le hacía señas para nada amables. Se asustó, devolvió sus pasos y dio un rodeo grande antes de ir al edificio por otro camino.

"Bueno, ya lo hiciste a Juan, gracias por contarme, no creo que haya sido la mejor decisión, pero veremos qué provecho podemos sacar de tu imprudencia". "Si, Julieta, ofrezco mis disculpas, pero tenía que hacerlo. Los medicamentos no están funcionando y todo lo que he hecho solo ha empeorado mi situación". "Tranquilo, vamos a cambiar el medicamento y seguiremos evaluando tus circunstancias".

“¡Nico, que sí, oí unas voces! Era como si escuchara la radio o la televisión, también sentí como corrientazos que pasaban por mis oídos o por mis manos, pero Julieta no me cree y ahora me tiene con otras pastas que me están afectando feo". "¿Hermano, y si lo que hay 
es una especie de foco de señales que se concentran en ese lugar? "Puede ser, por lo que me cuentas puede ser”. "¡No sé, Nico! lo cierto es que ahora cuando llego a la casa, hay siempre gente en la esquina, sobre todo mujeres y chicos parados debajo del canal, como tratando de ver qué es lo que yo experimenté el otro día”. “¡Umm!, lo peor es que esto contagie de curiosidad a la gente, debes tener cuidado".

Después de un par de semanas que transcurrieron como auténtico infierno en el que las señales lo atropellaban, las emociones lo abatían y la droga lo minaba por dentro y por fuera, Juan tomó una decisión totalmente insensata. Ese día no fue a la oficina, se quedó en el apartamento, alistó ropa y algunos utensilios en un morral; preparó comida, agua y areneras de los gatos como si fuera a salir varios días y dejó la casa a eso del medio día.

Ubicó el canal, recostó el morral sobre la pared del antejardin de la casa que daba sobre la esquina y se sentó en posición de flor de loto. Algunos dicen que un aura lo sobrecogió enseguida, otros vieron que el canal se materializó como una luz tenue, gris, otros incluso lo vieron levitar. Lo cierto es que, pese a todo, a las recomendaciones de la gente, a las agresiones de algunos vecinos e incluso a la represión policial de los agentes del CAI, Juan tomó por rutina salir al medio día de su casa y habitar esos ochenta centímetros, cada vez por más tiempo.

En la medida en que la gente se fue acostumbrando, lo dejaron tranquilo, se habituaron a ver esa especie de faquir criollo que pasaba horas y horas allí sentado con las manos mirando hacia el cielo, como si fueran receptores de señales invisibles que nadie lograba inteligir.

Unas tres semanas después de su primera salida, el aspecto de Juan era ya catastrófico, los vecinos se preocuparon, hicieron llamar a los familiares, a sus médicos, a las autoridades, pero lo único que lograban era que Juan se retirara por unas horas a su casa, para volver infaltablemente a su lugar sagrado.

“¡Nico, yo creo que llegó la hora de hacer algo!, yo sé que Juan es terco y manipulador y ahora que Julieta lo abandonó nos toca intervenir". "Si, Margarita, creo lo mismo, ¿si te parece vamos mañana?”. "Ayer Juan me llamó y me dijo que ya no sólo logra distinguir las voces de gente en distintos idiomas, sino que ha logrado descifrar otras señales y sus contenidos. Me habló de ondas radiales y televisivas, señales de internet y de datos de telefonía celular, canales alienígenas y hasta información proveniente de virus biológicos. Está loco de remate. Hace días que dejó de tomar sus medicamentos, según él porque le estaban bloqueando sus capacidades de comunicación".

Lo único que rompió la rutina fue la muerte de los gatos. Juan permaneció tres días dentro haciendo el duelo. El apartamento era un desastre. Cuando Nico y Margarita lo visitaron quedaron consternados. Margarita rompió en un llanto incontenible y Nico lo apretó en un abrazo prolongado que Juan soportó como vencido por la vida. Después les contó, por largos minutos, lo que había logrado descifrar. Mensajes de todo tipo, personales, corporativos, institucionales, mensajes de rutina, burocráticos, amorosos, amenazadores, secretos, 
advertencias, ruegos, instrucciones, mensajes abiertos, mensajes cifrados, reproches, agradecimientos, promesas, mensajes de todo tipo, millones de palabras, de imágenes, códigos que ya él había logrado interpretar de una manera increíble.

Los días los pasa ahora entre su reclusión en el manicomio, la visita semanal al canal y la escritura de mensajes a destinatarios que identifica, y que reciben por anticipado lo que debería llegar a sus dispositivos. Nico, Margarita, Julieta y hasta Clarita lo visitan con cierta frecuencia. Se le ve sereno. Dice haber encontrado la razón de su vida y por eso lo dejan tranquilo, le siguen la cuerda y lo lloran más tarde en sus casas, cuando a solas reviven los mejores tiempos del querido Juan, el hombre de la esquina. 